\title{
Evaluation of post-ERCP pancreatitis after biliary stenting with self-expandable metal stents vs. plastic stents in benign and malignant obstructions
}

\section{다)(1) $\odot(9)$}

Authors

Nichol S. Martinez ${ }^{1}$, Sumant Inamdar ${ }^{2}$, Sheila N. Firoozan ${ }^{1}$, Stephanie Izard ${ }^{3}$, Calvin Lee ${ }^{1}$, Petros C. Benias ${ }^{1}$, Arvind J. Trindade $^{1}$, Divyesh V. Sejpal ${ }^{1}$

Institutions

1 Donald and Barbara Zucker School of Medicine at Hofstra/Northwell, Gastroenterology, Manhasset, New York, United States

2 University of Arkansas for Medical Sciences, Gastroenterology, Little Rock, Arkansas, United States

3 Northwell Health Feinstein Institutes for Medical Research, Biostats, Manhasset, New York, United States

submitted 6.12.2020

accepted after revision 27.1.2021

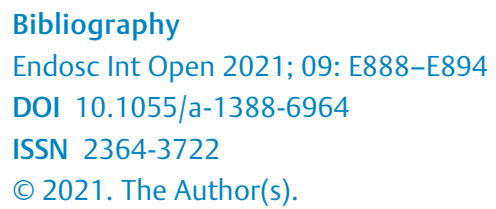
Commons Attribution-NonDerivative-NonCommercial License, permitting copying and reproduction so long as the original work is given appropriate credit. Contents may not be used for commercial purposes, or adapted, remixed, transformed or built upon. (https://creativecommons.org/licenses/by-nc-nd/4.0/)

Georg Thieme Verlag KG, Rüdigerstraße 14,

70469 Stuttgart, Germany

Corresponding author

Divyesh V. Sejpal, Donald and Barbara Zucker School of Medicine at Hofstra/Northwell, Gastroenterology, 300 Community Drive, Manhasset, NY 11030, United States Fax: +1-516-387-3930

dsejpal@northwell.edu

\section{ABSTRACT}

Background and study aims There are conflicting data regarding the risk of post-ERCP pancreatitis (PEP) with selfexpandable metallic stents (SEMS) compared to polyethylene stents (PS) in malignant biliary obstructions and limited data related to benign obstructions.

Patients and methods A retrospective cohort study was performed of 1136 patients who underwent ERCP for biliary obstruction and received SEMS or PS at a tertiary-care medical center between January 2011 and October 2016. We evaluated the association between stent type (SEMS vs PS) and PEP in malignant and benign biliary obstructions.

Results Among the 1136 patients included in our study, 399 had SEMS placed and 737 had PS placed. Patients with PS were more likely to have pancreatic duct cannulation, pancreatic duct stent placement, double guidewire technique, sphincterotomy and sphincteroplasty as compared to the SEMS group. On multivariate analysis, PEP rates were higher in the SEMS group (8.0\%) versus the PS group (4.8\%) (OR 2.27 [CI, 1.22, 4.24]) for all obstructions. For malignant obstructions, PEP rates were $7.8 \%$ and $6.6 \%$ for SEMS and plastic stents, respectively (OR $1.54[\mathrm{Cl}, 0.72,3.30])$. For benign obstructions the PEP rate was higher in the SEMS group (8.8\%) compared to the PS group (4.2\%) (OR 3.67 $[\mathrm{Cl}, 1.50,8.97])$. No significant differences between PEP severity were identified based on stent type when stratified based on benign and malignant.

Conclusions PEP rates were higher when SEMS were used for benign obstruction as compared to PS. For malignant obstruction, no difference was identified in PEP rates with use of SEMS vs PS.

\section{Introduction}

The most common post-procedure serious adverse event (AE) associated with endoscopic retrograde cholangiopancreatography (ERCP) is pancreatitis, which has an estimated incidence of $5 \%$ to $8 \%$ [1]. Multiple patient- and procedure-related factors have been identified that can affect the rate of post-ERCP pan- creatitis (PEP) [2-4]. Stents are used in ERCP to relieve biliary obstructions caused by malignant and benign lesions [5]. These stents, which are commonly made of metal (stainless steel or metal alloy) or plastic (polyethylene, polyurethane or Teflon), are available in a range of different lengths and diameters [6]. Self-expanding metallic stents (SEMS) may be uncovered or 
covered with materials such as polytetrafluoroethylene for ease in repositioning, removal and maximizing patency [7].

Previous studies examining the risks of PEP with placement of SEMS vs plastic stents (PS) have yielded conflicting results [8-10]. The majority of these studies had primarily focused on malignant biliary strictures. Coté et al. found the incidence of PEP to be considerably greater with SEMS compared to PS. In their retrospective study of malignant disease with 544 patients, the frequency of PEP in the SEMS group was $7.3 \%$, but only $1.3 \%$ in the PS group $(P=0.001)$ [11]. The rates of PEP in covered SEMS (cSEMS) and uncovered SEMS (uSEMS) were similar, $6.9 \%$ and $7.5 \%$, respectively $(P=0.82)$. In 2016, a meta-analysis comparing PS and SEMS in the treatment of malignant biliary strictures failed to identify a substantial difference in rates of PEP in eleven randomized clinical trials included in the study [10]. To our knowledge there has been no large meta-analysis, randomized controlled trial or cohort studies evaluating the rates of PEP with the use of SEMS and PS in benign biliary obstructions.

As there is conflicting data on the incidence of PEP after biliary stent placement, the aim of this study was to assess the association between stent type (SEMS or PS) and PEP in a large cohort of patients with both benign and malignant biliary obstructions.

\section{Patients and methods}

\section{Patient population/data collection}

This was a retrospective cohort study of 1136 patients who underwent ERCP and received SEMS or PS for biliary obstruction at a tertiary-care academic medical center between 01/2011 and 10/2016. All ERCPs were performed by experienced therapeutic endoscopists, each having performed more than 500 cases. All consecutive patients with malignant or benign biliary obstruction who underwent ERCP with placement of PS or SEMS were included. Malignancy was confirmed with pathology from ERCP brushings, endoscopic ultrasound with fine-needle aspiration, percutaneous biopsy, surgical resection or chart documentation. Stent choice and procedural techniques were made at the discretion of the performing endoscopist. Cases were excluded if documentation was unavailable, both PS and SEMS were utilized during the procedure, or if the patient had confirmed pancreatitis prior to the procedure. Patients who had undergone biliary stent placement were identified through our electronic database (Provation MD, Version 5.0.380.62, Minneapolis, MN) and subsequently the electronic medical record was reviewed up to 1 month post-procedure. PEP was defined as the development of abdominal pain after ERCP with a rise in amylase or lipase of greater than three times the upper limit of normal or radiographic findings consistent with pancreatitis. Pancreatitis severity was graded based on the ASGE Lexicon classification system [12].

\section{Variables of Interest}

The primary outcome of interest was the association between stent type (SEMS versus PS) and PEP. The patient charts were abstracted to evaluate clinical predictors for PEP that potential- ly modify or confound the association between stent type and PEP. These included patient age, gender, etiology for stent placement, lesion type (malignant or benign), and procedural characteristics. Etiology for stent placement were characterized by lesion type (malignant or benign) and origin (pancreatic or nonpancreatic cancer). Nonpancreatic cancers included cholangiocarcinoma, gallbladder cancer, lymphoma, and metastatic disease. Procedural characteristics included endoscopic biliary sphincterotomy (EBS), previous EBS, previous biliary stent placement, sphincteroplasty, precut sphincterotomy, double guidewire technique (DGT) and pancreatic duct (PD) cannulation and/or stent placement. Secondary outcomes of interest included the association between stent type (SEMS versus PS) and PEP stratified by lesion type (malignant versus benign), the association between metal stent type (cSEMS versus USEMS) and PEP, and the association between cancer type (pancreatic versus non-pancreatic) and PEP.

\section{Statistical analysis}

The main predictor of interest and covariates were summarized using descriptive statistics. Continuous variables were described using mean and standard deviation and compared between outcome groups using a two-sample $t$-test or MannWhitney $U$ test, as appropriate. Categorical variables were described using frequency and percent and compared between outcome groups using a chi-square test or Fisher exact test, as appropriate.

Prior to multivariable analysis, an interaction between stent type and lesion type was assessed to test whether there was a differential effect of stent type on PEP due to lesion type. Interaction was assessed by including main effects terms and an interaction term in a logistic regression model. Interaction was not found to be significant, but analyses were stratified by lesion type for clinical relevance as specified a priori. For each outcome, univariable analyses were performed using simple logistic regression models. Covariates that were specified to have suspected clinical importance based on previous studies (gender, PD stent placement, EBS, and precut sphincterotomy) as well as covariates whose univariable test had $P<0.25$ were investigated as confounders. Confounders were examined by considering the association between each potential confounder and the main predictor, the outcome of interest, and through a comparison of the adjusted beta coefficient with the unadjusted beta coefficient from the corresponding simple logistic regression model. A relaxed $P=0.25$ was used for to avoid excluding important variables, and a percent change $>10 \%$ between the unadjusted and adjusted beta coefficients was used as a cutoff for inclusion into the preliminary multivariable logistic regression model. As needed, the score selection method was used to select the best subset of covariates from the preliminary multivariable model based on the maximum model size to determine the final multivariable model.

The analysis for this paper was completed using SAS Studio version 3.8 (SAS Institute Inc., Cary, North Carolina, United States), and $P<0.05$ was considered statistically significant unless specified. 


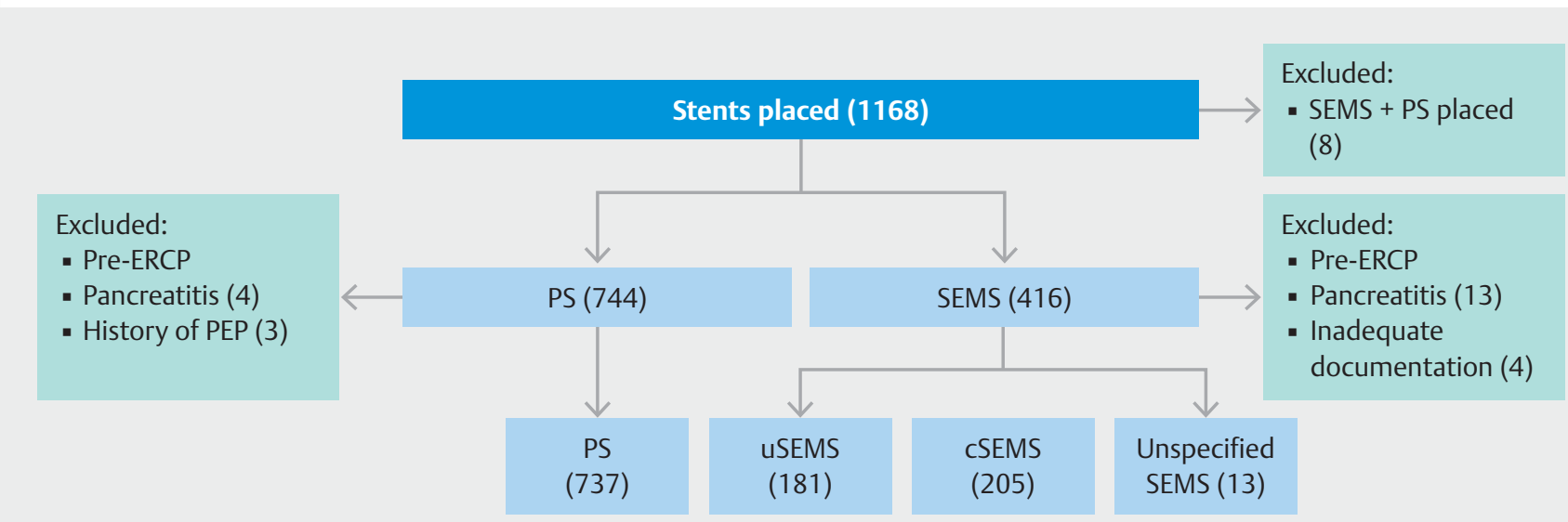

PS: Polyethylene Stents

SEMS: Self-Expandable Metallic Stents

uSEMS: Uncovered SEMS

CSEMS: Covered SEMS (Fully and Partially)

Fig. 1 Patient flowchart.

\section{Results}

Over a 5-year span, there were 1168 patients identified who underwent ERCP with placement of a biliary stent ( $\triangleright$ Fig. 1). 32 patients were excluded due to a combination of multiple stent types placed, pre-ERCP pancreatitis, history of post-ERCP pancreatitis and inadequate documentations, for a sample size of 1136. Of the remaining patients, 737 had PS placed and 399 had SEMS placed. Of the 399 SEMS included in our study, 181 (45\%) were USEMS, 205 (51\%) were cSEMS and 13 (3\%) were unspecified. There were a total of 660 benign obstructions with placement of 91 metal stents and 569 plastic stents, respectively ( $\downarrow$ Table 1 ). There were a total of 476 malignant obstructions with placement of 308 metal and 168 plastic stents, respectively.

Clinical characteristics are displayed below in $\mathbf{D a b l e} 2$. SEMS were more likely to be placed for malignant obstructions compared to PS $(77.2 \%$ vs. $22.8 \%, P<0.0001)$. Patients with metal stents had an average age of 72 , while those with PS had an average age of $70(P=0.0023)$. Patients who underwent PS placement were more likely to have PD cannulation, PD stent placement, DGT, EBS and sphincteroplasty as compared to the SEMS group ( $\triangleright$ Table 2 ). Patients who had SEMS placed were more likely to have a pre-existing biliary stent.

Of the 1136 patients included, $6.1 \%$ of patients developed PEP. Among the 69 patients who developed PEP; 28 (40.6\%) had mild PEP, 35 (50.7\%) had moderate PEP, and six $(8.7 \%)$ had severe PEP. There was no significant difference between severity of PEP based on stent type when stratified by benign ( $P=$ 0.4732 ) or malignant lesions $(P=0.0912)$.

On univariable analysis, SEMS was significantly associated with PEP compared to PS for all types of biliary obstruction (OR \& $95 \% \mathrm{Cl}$ for univariable) ( Table 3 ). Same session EBS, DGT and PD cannulation were identified as potential risk factors for subsequent development of PEP whereas prior biliary stent and prior EBS were potential protective factors. Patient age, gender, etiology of obstruction (malignant vs benign), PD stent, precut sphincterotomy and sphincteroplasty did not significantly impact PEP rates. After controlling for confounding variables, SEMS placement (OR: 2.27 [95\%Cl, 1.22-4.24]) and use of DGT (OR: 2.67 [95\%Cl, 1.19-6.12]) was associated with the development of PEP among those with any type of biliary obstruction. The presence of prior biliary stents was the only variable found to significantly reduce the risk of PEP (OR: $0.25[95 \% \mathrm{Cl}$, $0.10-0.64])$.

When assessing PEP by specific type of obstruction (benign versus malignant), we found that among those with benign biliary obstructions, SEMS placement (8.8\%) compared to PS placement (4.2\%) was associated with PEP (OR: $3.67[95 \% \mathrm{Cl}$, 1.50-8.97]) ( Table 4). However, among those with malignant obstructions we did not identify a statistically significant association between stent type and PEP (OR: 1.54 [95\%Cl, 0.723.30]) ( $>$ Table 5). No significant difference in PEP was detected between use of uSEMS (6.1\%) compared to cSEMS (9.3\%), nor between pancreatic ( $7.4 \%$ ) compared to nonpancreatic cancer (7.2\%).

\section{Discussion}

PS are often used for the management of biliary obstructions owing to the reduced initial cost and if a diagnosis of malignancy has not been achieved. SEMS are now being increasingly utilized for both malignant and benign disease as they offer improved patency rates and may be more cost effective in select patient populations. Several studies have suggested an increased risk of PEP with the use of SEMS owing to its increased axial force compared to PS $[13,14]$. Most studies that have evaluated the rates of PEP have done so in relation to the treatment of malignant lesions. To our knowledge, this is the largest study 
- Table 1 Etiologies of benign biliary obstruction.

\begin{tabular}{|l|c|c|}
\hline Etiology & Plastic, $\mathbf{N}(\%)$ & Metal, N (\%) \\
\hline Ampullary mass, $\mathrm{n}(\%)$ & $1(0.2)$ & $0(0)$ \\
\hline Bile leak/fistula, $\mathrm{n}(\%)$ & $65(11.4)$ & $12(13.2)$ \\
\hline Cholangitis, $\mathrm{n}(\%)$ & $79(13.9)$ & $5(5.5)$ \\
\hline Hemobilia, $\mathrm{n}(\%)$ & $0(0)$ & $3(3.3)$ \\
\hline PSC, $\mathrm{n}(\%)$ & $8(1.4))$ & $2(2.2$ \\
\hline Papillary stenosis, $\mathrm{n}(\%)$ & $3(0.5)$ & $0(0)$ \\
\hline Stent change, $\mathrm{n}(\%)$ & $14(2.5)$ & $10(11.0)$ \\
\hline Stones/sludge, $\mathrm{n}(\%)$ & $299(52.5)$ & $23(25.3)$ \\
\hline Stricture, $\mathrm{n}$ (\%) & $100(17.6)$ & $36(39.6)$ \\
\hline Total & 569 & 91 \\
\hline PSC, primary sclerosing cholangitis. & & \\
\hline
\end{tabular}

to evaluate PEP rates associated with PS vs. SEMS and the only study to address rates of PEP in both benign and malignant disease independently. As expected, there were more SEMS than PS placed for malignant etiologies in our study. Generally, patients with PS placement were more likely to undergo procedural techniques thought to increase the risk of PEP compared to patients with SEMS placement ( $\triangleright$ Table 2 ). This includes DGT, PD cannulation, sphincteroplasty and EBS. When control- ling for these factors, SEMS was associated with PEP before stratifying by type of obstruction (benign versus malignant).

Looking exclusively at malignant obstructions, we did not find a significant difference in the rates of PEP based on the type of stent placed. Although these findings are contrary to the conclusion of Cote et al. from their large retrospective series, our findings are consistent with the recent large meta-analysis by Almadi et al. $[10,11]$. Experts have suggested SEMS have the potential to precipitate PEP due to their larger diameter size causing obstruction of the pancreatic orifice when expanded [11]. This did not appear to be the case with malignant obstructions in our study. On analysis of benign obstructions, we identified an association between SEMS and PEP compared to PS when controlling for confounding variables, including sphincterotomy. Studies have suggested a dilated PD, as is more commonly seen in malignant obstructions, may decrease the likelihood of PEP, particularly in the setting of PD cannulation $[15,16]$. This may be one explanation for differences found in the analysis of malignant obstructions compared to benign obstructions.

There has been limited data regarding the risks of PEP in benign biliary disease. In a prospective study of 187 patients that were treated with SEMS for benign biliary strictures of various etiologies, a PEP rate of $2.7 \%$ was found related to stent placement or stent removal [7]. In a randomized, prospective study of 60 patients treated with SEMS or multiple plastic stents for biliary strictures due to chronic pancreatitis, a PEP rate of $0.5 \%$ was found in approximately 200 procedures [17].

- Table 2 Clinical characteristics of patients who received self-expandable metallic stents and polyethylene stents.

\begin{tabular}{|c|c|c|c|}
\hline Variable & SEMS ( $n=399), n$ (\%) & PS (n= 737), n (\%) & $P$ value \\
\hline \multicolumn{4}{|l|}{ Patient characteristics } \\
\hline - Age, mean (SD) & $72.1(12.1)$ & $69.6(14.8)$ & 0.0023 \\
\hline - Female, n (\%) & $340(46.1)$ & $185(25.0)$ & 0.9401 \\
\hline \multicolumn{3}{|l|}{ Lesion Type } & \multirow[t]{3}{*}{$<.0001$} \\
\hline - Malignant, n (\%) & $308(77.2)$ & $168(22.8)$ & \\
\hline - Benign, n (\%) & $91(22.8)$ & $569(77.2)$ & \\
\hline \multicolumn{4}{|l|}{ Procedure characteristics } \\
\hline - History of EBS, n (\%) & $61(15.3)$ & $130(17.6)$ & 0.3118 \\
\hline - History of biliary stent, n (\%) & $147(36.8)$ & $175(23.7)$ & $<.0001$ \\
\hline - EBS, n (\%) & $185(46.4)$ & $442(60.0)$ & $<.0001$ \\
\hline - Sphincteroplasty, n (\%) & $6(1.5)$ & $36(4.9)$ & 0.0039 \\
\hline - Precut sphincterotomy, n (\%) & $11(2.8)$ & $16(2.2)$ & 0.5360 \\
\hline - DGT, n (\%) & $15(3.8)$ & $57(7.7)$ & 0.0087 \\
\hline - PD cannulation, n (\%) & $51(12.8)$ & $132(17.9)$ & 0.0248 \\
\hline - PD stent placement, n (\%) & $16(4.0)$ & $73(9.9)$ & 0.0004 \\
\hline
\end{tabular}


- Table 3 Multivariable model of all obstructions $(\mathrm{N}=1136)$.

\begin{tabular}{|c|c|c|c|c|}
\hline Variable & $\begin{array}{l}\text { PEP rate with variable, } \\
\text { n (\%) }\end{array}$ & $\begin{array}{l}\text { PEP rate w/o variable, } \\
\text { n (\%) }\end{array}$ & $\begin{array}{l}\text { Univariable OR } \\
(95 \% \mathrm{Cl})\end{array}$ & $\begin{array}{l}\text { Multivariable OR } \\
(95 \% \mathrm{Cl})\end{array}$ \\
\hline SEMS placement & $32(8.0)$ & $35(4.8)$ & $1.75(1.07,2.87)$ & $2.27(1.22,4.24)$ \\
\hline Age, mean (sd) & - & - & $0.99(0.97,1.01)$ & - \\
\hline Female gender & $37(7.1)$ & $30(4.9)$ & $1.47(0.89,2.41)$ & - \\
\hline Etiology (Malignant) & $35(7.4)$ & $32(4.9)$ & $1.56(0.95,2.55)$ & $0.97(0.52,1.81)$ \\
\hline Previous EBS & $4(2.1)$ & $63(6.7)$ & $0.30(0.11,0.83)$ & - \\
\hline Previous Biliary Stent & $6(1.9)$ & $61(7.5)$ & $0.23(0.10,0.53)$ & $0.25(0.10,0.64)$ \\
\hline EBS & $45(7.2)$ & $22(4.3)$ & $1.71(1.01,2.89)$ & $0.97(0.54,1.74)$ \\
\hline Sphincteroplasty & $1(2.4)$ & $66(6.0)$ & $0.38(0.05,2.81)$ & - \\
\hline Precut sphincterotomy & $2(7.4)$ & $65(5.9)$ & $1.29(0.30,5.54)$ & - \\
\hline PD cannulation & $22(12.0)$ & $45(4.7)$ & $2.76(1.61,4.72)$ & $1.55(0.78,3.10)$ \\
\hline PD stent & $8(9.0)$ & $59(5.6)$ & $1.65(0.76,3.58)$ & - \\
\hline DGT & $13(18.1)$ & $54(5.1)$ & $4.36(2.29,8.30)$ & $2.67(1.19,6.12)$ \\
\hline
\end{tabular}

SEMS, self-expandable metallic stent; PEP, post-ERCP pancreatitis; PD, pancreatic duct; EBS, endoscopic biliary sphincterotomy; DGT, double guidewire technique.

- Table4 Multivariable model to assess for post ERCP pancreatitis (PEP) risk factors in patients with benign obstructions $(N=660)$.

\begin{tabular}{|c|c|c|c|c|}
\hline Variable & $\begin{array}{l}\text { PEP rate with variable, } \\
\mathrm{n}(\%)\end{array}$ & PEP rate w/o variable (\%) & $\begin{array}{l}\text { Univariable OR } \\
(95 \% \mathrm{Cl})\end{array}$ & $\begin{array}{l}\text { Multivariable OR } \\
(95 \% \mathrm{CI})\end{array}$ \\
\hline SEMS placement & $8(8.8)$ & $24(4.2)$ & $2.19(0.95,5.03)$ & $3.67(1.50,8.97)$ \\
\hline Age & - & - & $0.99(0.97,1.01)$ & - \\
\hline Female gender & $19(6.2)$ & $13(3.7)$ & $1.74(0.84,3.58)$ & - \\
\hline Previous EBS & $4(2.9)$ & $28(5.4)$ & $0.52(0.18,1.50)$ & - \\
\hline Previous biliary stent & $3(1.5)$ & $29(6.3)$ & $0.23(0.07,0.77)$ & $0.22(0.06,0.76)$ \\
\hline EBS & $18(5.2)$ & $14(4.5)$ & $1.17(0.57,2.39)$ & - \\
\hline Sphincteroplasty & $1(2.6)$ & $31(5.0)$ & $0.50(0.07,3.77)$ & - \\
\hline Precut sphincterotomy & $1(8.3)$ & $31(4.8)$ & $1.81(0.23,14.46)$ & - \\
\hline PD Cannulation & $10(12.2)$ & $22(3.8)$ & $3.51(1.60,7.71)$ & - \\
\hline PD stent & $3(7.7)$ & $29(4.7)$ & $1.70(0.50,5.85)$ & - \\
\hline DGT & $8(17.8)$ & $24(3.9)$ & $5.33(2.24,12.66)$ & $4.76(1.93,11.74)$ \\
\hline
\end{tabular}

SEMS, self-expandable metallic stent; PEP, post-ERCP pancreatitis; PD, pancreatic duct; EBS, endoscopic biliary sphincterotomy; DGT, double guidewire technique.

We also evaluated several suspected risk factors associated with the development of PEP. PEP rates were higher in patients who had undergone DGT; this was true for both benign and malignant obstructions. For all obstructions, previous biliary stent placement had a protective effect on the development of PEP. Similar to previous studies, covered metal stents did not have a significant impact on PEP compared to uncovered stents [11]. When comparing pancreatic cancers to nonpancreatic cancers, there was no significant difference in the PEP rates with stent placement. However, two studies had previously identified malignant obstructions secondary to nonpancreatic cancers as a risk factor for PEP with the use of SEMS compared to pancreatic cancers $[18,19]$.

There are certain limitations to our study. Given the retrospective nature of our study, the choice of SEMS vS PS was made at that discretion of the endoscopist involved in the case, which may have led to selection bias. Based on the available documentation, we are unable to comment on whether the location of the obstruction (distal vs proximal) influences the rate of PEP. Limitations in EMR documentation prevented us from controlling for the use of pre-procedure or post-procedure use of rectal nonsteroidal anti-inflammatory drugs, peri- 
- Table 5 Multivariable model to assess for post ERCP pancreatitis (PEP) risk factors in patients with malignant obstructions ( $N=476)$.

\begin{tabular}{|c|c|c|c|c|}
\hline Variable & $\begin{array}{l}\text { PEP rate with variable, } \\
\text { n (\%) }\end{array}$ & $\begin{array}{l}\text { PEP rate } w / 0 \text { variable, } \\
n(\%)\end{array}$ & $\begin{array}{l}\text { Univariable OR } \\
(95 \% \mathrm{CI})\end{array}$ & $\begin{array}{l}\text { Multivariable OR } \\
(95 \% \mathrm{CI})\end{array}$ \\
\hline SEMS placement & $24(7.8)$ & $11(6.6)$ & $1.21(0.58,2.53)$ & $1.54(0.72,3.30)$ \\
\hline Age & - & - & $0.99(0.96,1.02)$ & - \\
\hline Female gender & $18(8.2)$ & $17(6.6)$ & $1.26(0.64,2.52)$ & - \\
\hline Previous EBS & $0(0.0)$ & $35(8.2)$ & $0.11(0.01,1.82)$ & - \\
\hline Previous biliary stent & $3(2.4)$ & $32(9.1)$ & $0.25(0.07,0.82)$ & - \\
\hline EBS & $27(9.6)$ & $8(4.1)$ & $2.51(1.11,5.64)$ & $2.62(1.15,5.99)$ \\
\hline Sphincteroplasty & $0(0.0)$ & $35(7.4)$ & $3.28(0.00,21.93)$ & - \\
\hline Precut sphincterotomy & $1(6.7)$ & $34(7.4)$ & $0.90(0.11,7.03)$ & - \\
\hline PD Cannulation & $12(11.9)$ & $23(6.1)$ & $2.06(0.99,4.31)$ & - \\
\hline PD stent & $5(10.0)$ & $30(7.0)$ & $1.47(0.54,3.97)$ & - \\
\hline DGT & $5(18.5)$ & 30 (6.9) & $3.17(1.12,8.97)$ & $3.08(1.07,8.89)$ \\
\hline
\end{tabular}

SEMS, self-expandable metallic stent; PEP, post-ERCP pancreatitis; PD, pancreatic duct; EBS, endoscopic biliary sphincterotomy; DGT, double guidewire technique.

procedural hydration, and difficult cannulation [20-22]. Relatively few of our patients underwent sphincteroplasty, DGT, or precut sphincterotomy. Further studies are needed to evaluate the impact of these risk factors on PEP.

\section{Conclusions}

In conclusion, we found SEMS placement to be associated with PEP for benign obstructions relative to PS, but no statistically significant difference when SEMS were placed for malignant obstructions compared to PS. Further prospective studies are necessary to evaluate the relative risk for PEP in patient's undergoing ERCP for benign obstructions and to identify specific risk factors for development of PEP.

\section{Competing interests}

Divyesh V. Sejpal - Consulting for Boston Scientific and Olympus Arvind J. Trindade - Consulting for Olympus and Pentax

References

[1] Andriulli A, Loperfido S, Napolitano G et al. Incidence rates of postERCP complications: a systematic survey of prospective studies. Am J Gastroenterol 2007; 102: 1781-1788

[2] Testoni PA, Testoni S, Giussani A. Difficult biliary cannulation during ERCP: how to facilitate biliary access and minimize the risk of postERCP pancreatitis. Dig Liver Dis 2011; 43: 596-603

[3] Chen J], Wang XM, Liu XQ et al. Risk factors for post-ERCP pancreatitis: a systematic review of clinical trials with a large sample size in the past 10 years. Eur J Med Res 2014; 19: 26
[4] Mazaki T, Masuda H, Takayama T. Prophylactic pancreatic stent placement and post-ERCP pancreatitis: a systematic review and metaanalysis. Endoscopy 2010; 42: 842-853

[5] Catalano O, De Bellis M, Sandomenico F et al. Complications of biliary and gastrointestinal stents: MDCT of the cancer patient. AJR Am J Roentgenol 2012; 199: W187-W196

[6] Pfau PR, Pleskow DK. ASGE Technology Assessment Committee. et al. Pancreatic and biliary stents [published correction appears in Gastrointest Endosc 2013; 78: 193-5]. Gastrointest Endosc 2013; 77: 319327

[7] Devière J, Nageshwar Reddy D, Püspök A et al. Successful management of benign biliary strictures with fully covered self-expanding metal stents. Gastroenterology 2014; 147: 385-e15

[8] Kaassis M, Boyer J, Dumas R et al. Plastic or metal stents for malignant stricture of the common bile duct? Results of a randomized prospective study. Gastrointest Endosc 2003; 57: 178-182

[9] Prat F, Chapat O, Ducot B et al. A randomized trial of endoscopic drainage methods for inoperable malignant strictures of the common bile duct. Gastrointest Endosc 1998; 47: 1-7

[10] Almadi MA, Barkun A, Martel M. Plastic vs. self-expandable metal stents for palliation in malignant biliary obstruction: a series of metaanalyses. . Am J Gastroenterol 2017; 112: 260-273

[11] Coté GA, Kumar N, Ansstas M et al. Risk of post-ERCP pancreatitis with placement of self-expandable metallic stents. Gastrointest Endosc 2010; 72: 748-754

[12] Cotton PB, Eisen GM, Aabakken L et al. A lexicon for endoscopic adverse events: report of an ASGE workshop. Gastrointest Endosc 2010; 71: 446-454

[13] Kato S, Kuwatani M, Hayashi T et al. Inutility of endoscopic sphincterotomy to prevent pancreatitis after biliary metal stent placement in the patients without pancreatic duct obstruction. Scand J Gastroenterol 2020; 55: 503-508

[14] Isayama H, Nakai Y, Hamada T et al. Understanding the mechanical forces of self-expandable metal stents in the biliary ducts. Curr Gastroenterol Rep 2016; 18: 64

[15] Ishikawa-Kakiya Y, Shiba M, Maruyama H et al. Risk of pancreatitis after pancreatic duct guidewire placement during endoscopic retrograde cholangiopancreatography. PLoS One 2018; 13: e0190379 
[16] Sugawara S, Arai Y, Sone M et al. Frequency, severity, and risk factors for acute pancreatitis after percutaneous transhepatic biliary stent placement across the papilla of Vater. Cardiovasc Intervent Radiol 2017; 40: 1904-1910

[17] Haapamäki C, Kylänpää L, Udd M et al. Randomized multicenter study of multiple plastic stents vs. covered self-expandable metallic stent in the treatment of biliary stricture in chronic pancreatitis. . Endoscopy 2015; 47: 605-610

[18] Kawakubo K, Isayama H, Nakai Y et al. Risk factors for pancreatitis following transpapillary self-expandable metal stent placement. Surg Endosc 2012; 26: 771-776

[19] Shimizu S, Naitoh I, Nakazawa T et al. Predictive factors for pancreatitis and cholecystitis in endoscopic covered metal stenting for distal malignant biliary obstruction. J Gastroenterol Hepatol 2013; 28: 6872

[20] Radadiya D, Devani K, Arora S et al. Peri-procedural aggressive hydration for post endoscopic retrograde cholangiopancreatography (ERCP) pancreatitis prophylaxsis: meta-analysis of randomized controlled trials. Pancreatology 2019; 19: 819-827

[21] Patai Á, Solymosi N, Mohácsi L et al. Indomethacin and diclofenac in the prevention of post-ERCP pancreatitis: a systematic review and meta-analysis of prospective controlled trials. Gastrointest Endosc 2017; 85: 1144-1156.e1

[22] Vandervoort J, Soetikno RM, Tham TC et al. Risk factors for complications after performance of ERCP. Gastrointest Endosc 2002; 56: 652656 